\title{
Distribution of the Terminals of the Descending Abdominal Aorta in Chinchillas
}

\author{
Cristian MARTONOS ${ }^{1 *}$, Cristian DEZDROBITU ${ }^{1}$, Vasile RUS ${ }^{1}$, Viorel MICLĂUŞ ${ }^{1}$, Irina IRIMESCU ${ }^{1}$, \\ Aurel DAMIAN ${ }^{1}$
}

${ }^{1}$ University of Agricultural Sciences and Veterinary Medicine, Cluj-Napoca, Romania;

*Corresponding author, e-mail: martonosolimpiu@yahoo.com

Bulletin UASVM Veterinary Medicine 71(2) / 2014,

Print ISSN 1843-5270; Electronic ISSN 1843-5378

DOI:10.15835/buasvmcn-vm:

\begin{abstract}
Our study was made on 3 clinically healthy, Chinchila laniger females, weighting 600 grams. These animals were commercially slaughtered for their fur. The descending abdominal aorta (A. aorta descendens abdominalis) was identified and then injected with a colored substance, followed by anatomical dissection. The stratigraphic dissection underlined the descending abdominal aorta (A. aorta descendens abdominalis) and its terminals, represented by two common iliac arteries (A. iliaca communis) forming a right angle at their origin point. Only one specimen presented a median sacral artery (A. sacralis mediana).
\end{abstract}

Keywords: abdominal aorta, Chinchila laniger, terminal arteries

\section{INTRODUCTION}

Chinchillas originate from South America, where they live at altitudes above $2000 \mathrm{~m}$ (Bud et al., 2006; Bura, 2003). They are taxonomically placed in the Mamalia class, Theria subclass, Eutheria clade, Rodentia order, Hystricomorpha suborder, Chinchilidae family, Chinchilla species. Spanish conquistadors gave them the name of "chinchilla" in the sixteenth century, after that of the Inca tribe called "Chinca". Natives of this tribe hunted chinchillas for fur that they used for clothes making, but also for their exceptionally tasting meat. The highest quality fabrics were woven from the hair that chinchillas used to line their nests with. The first writing mentioning chinchilla dates from 1591 and belongs to Joseph de Acosta (Botha, 2009). In our country, chinchillas were imported only in the 80s, during the development of the husbandry sector for fur animals. Although bred in captivity as fur animals, as of late, they are increasingly gaining popularity as pets.

The aorta is the largest artery vessel in the whole body (Barone, 2006). From an anatomic point of view, it can be divided into several segments. The first segment is represented by the ascending aorta (Aorta ascendens) that originates at the base of the left ventricle (Ventriculus dexter) (Damian, 2007). The ascending aorta (Aorta ascendens) extends from its origin to the point of emergence of the brachiocephalic trunk (Truncus Brachiocephalicus), where it is followed by the second segment: the aortic arch (Arcus Aortae). The third segment is represented by the descending aorta (A. aorta descendens) (Damian, 2007). The latter is also in its turn systematized into two segments, depending on its placement relative to the diaphragm: the descending thoracic aorta (Aorta Thoracica) and the descending abdominal aorta (Aorta Abdominalis). The descending aorta (Aorta Descendens) emits along its whole length both visceral and parietal branches. The terminals of the descending abdominal aorta vary according to the species (Barone, 2006). The descending abdominal aorta (Aorta Descendens) supplies arterial blood to the whole pelvic limb and to the organs of the pelvic cavity, through its terminals and through their branches.

Medical research is another domain that begins to pay more and more attention to this species, that is being used increasingly often as 
an experimental model for the study of renal anatomy, of the cardiovascular system, of the arterial vascularization of the brain and of the ear, of the ovarian cycle and for endocrinology research. Other areas in which chinchillas are used include studies of respiratory and gastrointestinal pathology, leading to the appearance in recent years of more detailed descriptions of the anatomy of this species (Stan F, 2013; Stan et al., 2014).

Considering the size of these animals, we can assert that studies regarding the cardiovascular system in chinchillas are rather difficult to perform due to the reduced size the arterial vessels.

This research focuses on the anatomical description of the terminals of the descending abdominal aorta, as well as on the identification of individual variations.

\section{MATERIALS AND METHODS}

The biologic material consisted of 3 female chinchillas from a private husbandry, commercially slaughtered for fur. The animals were screened through a rigorous clinical examination prior to slaughter and declared clinically healthy. The work method comprised the inspection and the stratigraphic and regional dissections of each specimen. Each stage of the dissection was photographed and observational notes were taken. We have also noted and photographed anatomical differences.

Following the skinning, we proceeded to open the abdominal cavity along the linea alba and isolate the abdominal artery. The next steps consisted of the catheterization of the aorta with the help of a $24 \mathrm{G}$ catheter and performing a flushing with a physiological saline and heparin solution. We have injected through the same catheter into the aorta a quantity of $10 \mathrm{ml}$ of a red acrylic coloring agent and latex mix, in a 3:1 ratio. After the injection, the carcasses were immersed into a formaldehyde fixating solution for 5 days. After the expiration of the fixation period, we have performed the stratigraphic dissection, starting from the abdominal aorta into the pelvic cavity.

\section{RESULTS AND DISCUSSION}

After the removal of the gastro-intestinal mass and of the other organs from the abdominal cavity, we have identified and isolated the descending abdominal aorta (A. aorta descendens) and performed a stratigraphic dissection in order to isolate its terminals in all three studied specimens. Thus, 2 of the females presented 2 terminals (fig. 1 ), represented by the right common iliac artery (A. iliaca communis dextra) and the left common iliac artery ( $A$. iliaca communis sinister). One individual presented 3 terminals (fig. 2): besides the two common iliac arteries (left and right) we have also identified the median sacral artery $(A$. sacralis mediana). The common iliac arteries (left and right) branch off from the aorta at the level of the last lumbar vertebrae (Vertebrae lumbales) (L5-L6). The origins of the right common iliac artery (A. iliaca communis dextra) and of the left common iliac artery (A. iliaca communis sinister) form a right angle $\left(90^{\circ}\right)$.

The median sacral artery (A. sacralis mediana) detaches itself from the dorsal surface of the descending abdominal aorta (Aorta Descendens) slightly before its terminal bifurcation. This artery has a cranio-caudal path, on the ceiling of the pelvic cavity and is continued by the medial coccygeal artery (A. caudalis mediana). The median sacral artery (A. sacralis mediana) gives off numerous dorsal lumbar (Rami lumbalis) and sacral branches (Rami sacrales).

The common iliac arteries (A. iliaca communis) traverse a dorso-ventral, cranio-caudal path over a distance of 4 to $9 \mathrm{~mm}$ at the end of which they present a terminal bifurcation into the external $(A$. iliaca externa) and internal iliac arteries (A. iliaca interna). We have also noticed that the diameter of the two terminals is not even. The external iliac arteries (A. iliaca externa) are much more voluminous than the internal iliac arteries $(A$. iliaca interna).

The external iliac artery (A. iliaca externa) has a descending path, oriented towards the femoral ring (Anulus femoralis) (fig. 3) where it is continued by the femoral artery (A. femoralis), similarly to the topography described in horses, that we hold as reference species for the comparative veterinary anatomy (Stan et al., 2006). The external iliac artery (A. iliaca externa) emits a main branch represented by the uterine artery (A. uterina). The uterine artery gives off the umbilical artery $(A$. umbilicalis), the arterial branches for the bladder (Aa. vesicales craniales), the vaginal branches (Ramus vaginalis) (fig. 4, 5), as well as several branches servicing the ventro-lateral muscles of the abdomen. It then orients itself cranially inbetween the laminae of the broad ligament. At this 


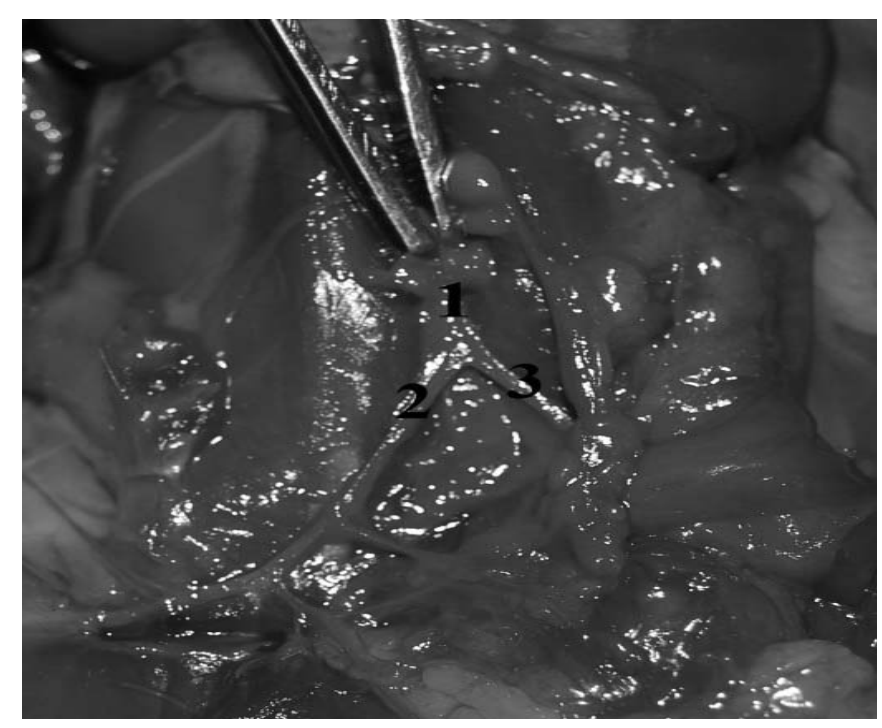

Fig. 1. Terminals of the descending abdominal aorta: 1. Descending abdominal aorta; 2 . Right common iliac artery; 3. Left common iliac artery.

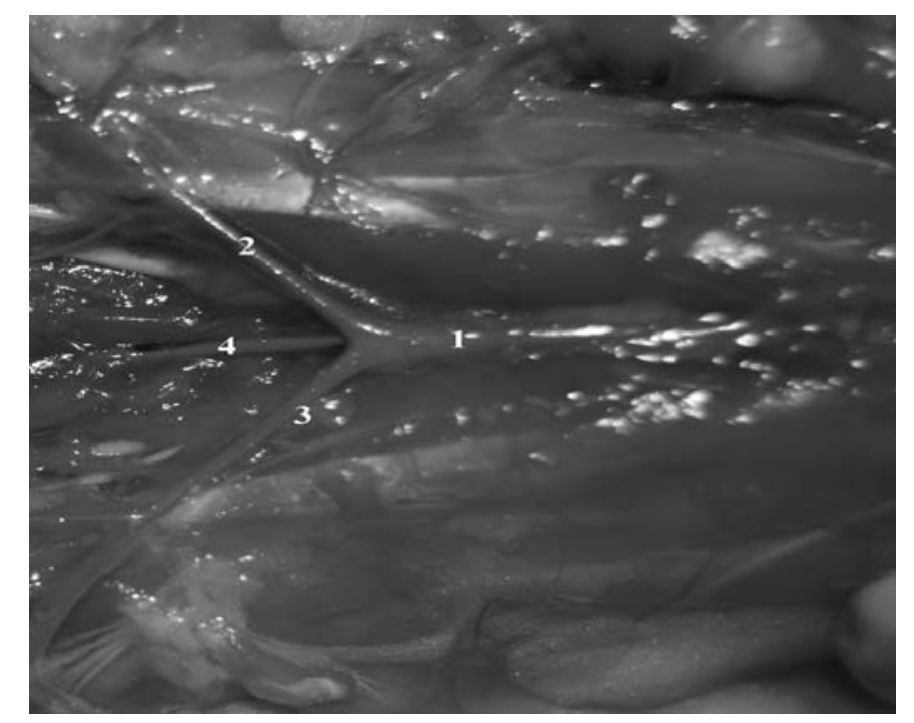

Fig. 2. Terminals of the descending abdominal aorta: 1. Descending abdominal aorta; 2. Right common iliac artery;

3. Left common iliac artery; 4. Median sacral artery.

level, the uterine artery (A. uterina) emits multiple arterial branches servicing the cervix, the body and the horns of the uterus. The uterine artery ends by a bifurcation into two ovarian branches. The ovarian branches of the uterine artery form anastomoses with the terminals of the ovarian artery (A. ovarica).

The internal iliac artery (A. iliaca interna) gives off the following branches: the internal pudendal artery ( $A$. pudenda interna), the cranial gluteal artery (A. glutea cranialis), the obturator artery (A. obturatoria) and the caudal gluteal artery (A. glutea caudalis). The internal pudendal artery has a ventro-caudal path from its origin and emits arteries servicing the rectum, the vagina, the vaginal vestibule, as well as the perineal artery. The cranial gluteal artery (A. glutea cranialis) gives off on its path the iliolumbar artery, which distributes itself into the muscles of croup. The caudal gluteal artery terminals service the biceps femoris, the semitendinosus and the semimembranosus muscles. 
The results that we have obtained regarding the terminals of the descending abdominal aorta are similar to those described by other authors (Çevik-Demirkana et al. 2010), but we have identified in one female the presence of three terminals. We consider this situation as representing an individual variation. In this case, the topography of the terminals is similar to the common norm described by Barone (1996) in rabbits and in humans. The origin, the path and the distribution of the median sacral artery $(A$. sacralis mediana) that we have observed in one of the specimens is also similar with that described in rabbits (Barone, 1996).

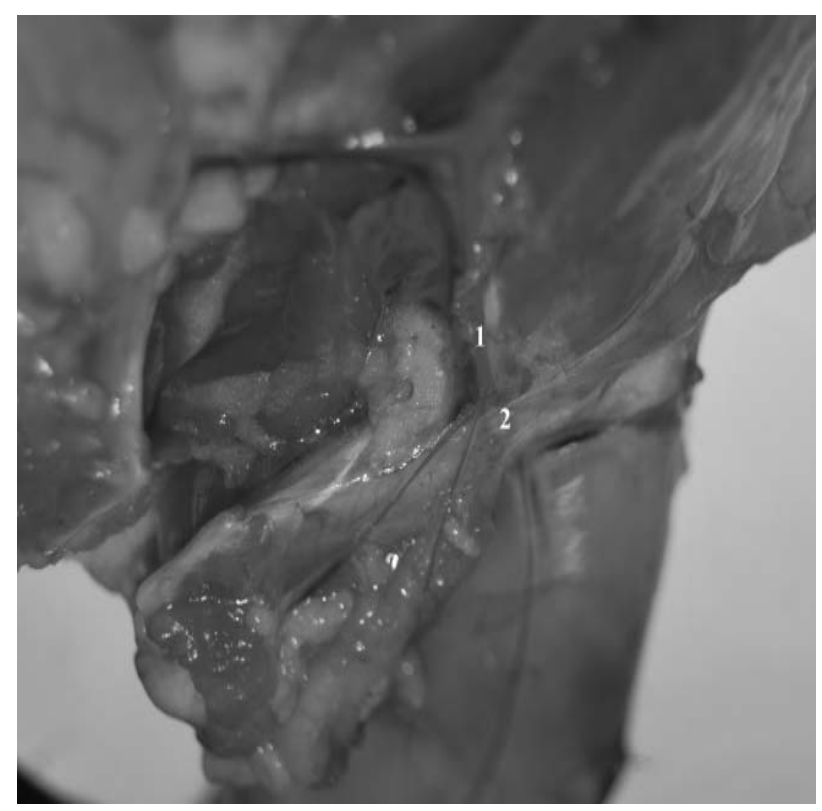

Fig. 3. Path of the external iliac artery: 1. External iliac artery; 2. Femoral ring.

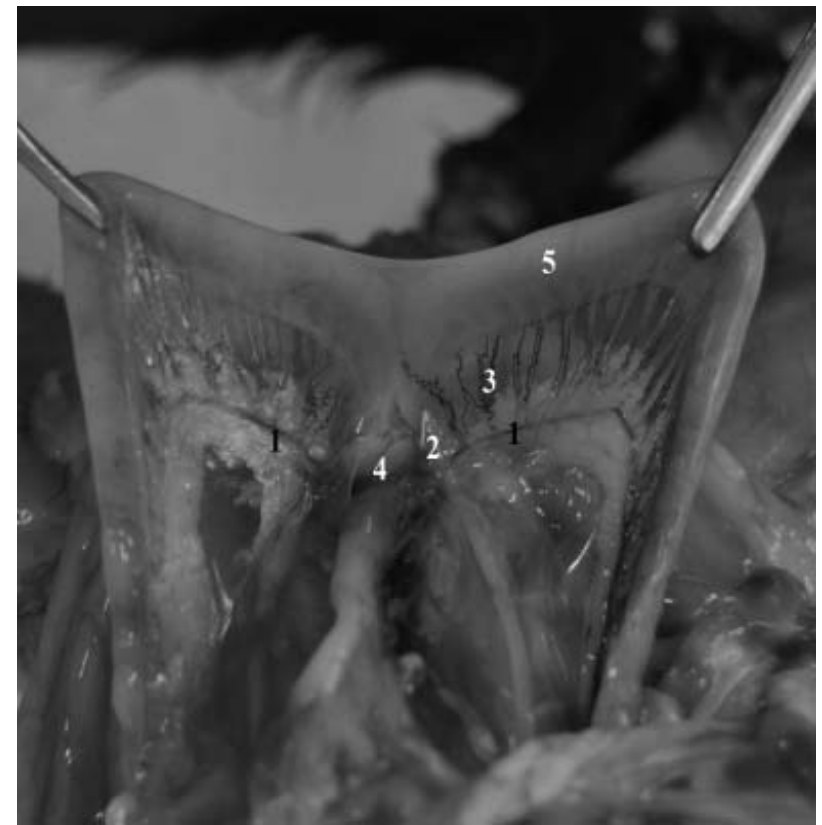

Fig. 4. Dorsal view of the branches of the uterine artery: 1. Uterine artery; 2 . Arterial branches for the cervix; 3. Uterine branches; 4. Cervix; 5 . Uterine horn. 


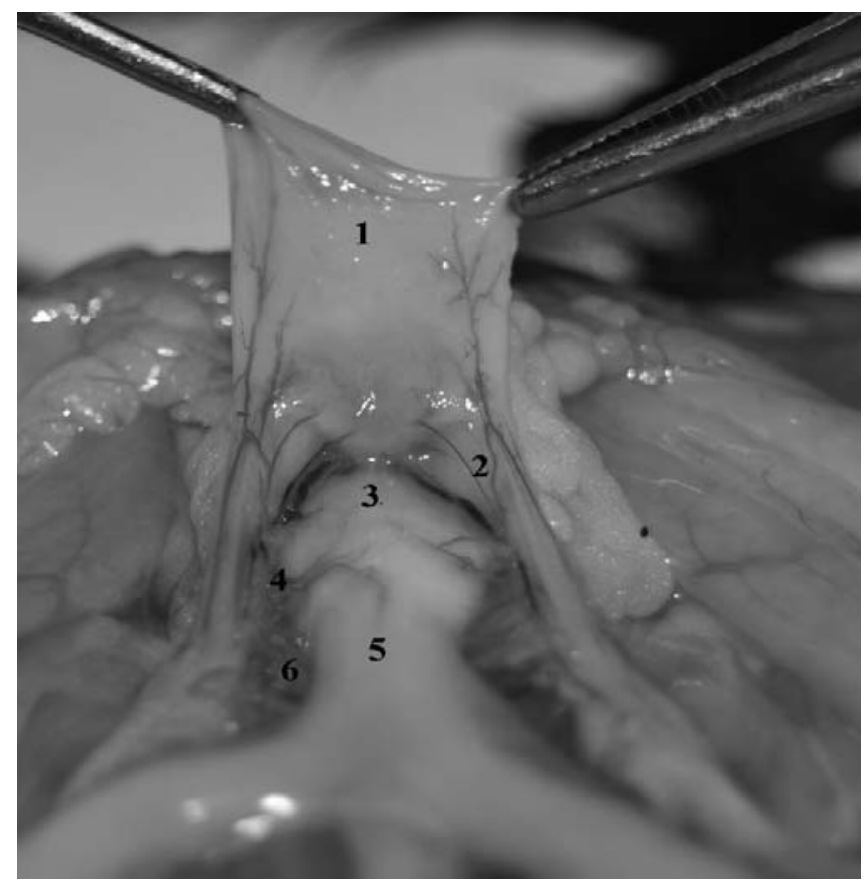

Fig. 5. Ventral view of the branches of the uterine artery: 1. Urinary bladder; 2 . Branches for the bladder; 3 . Cervix; 4. Arterial branches for the cervix; 5 . Uterine body; 6. Arterial branches for the uterine body.

In the animals that we have studied, the length of the common iliac arteries (A. iliaca communis) ranged from 4 to $9 \mathrm{~mm}$, while Çevik-Demirkan (2010) describes a 7 to $9 \mathrm{~mm}$ path. We consider that these differences in common iliac arteries length are due to individual variability.

Our results concerning the external iliac arteries (A. iliaca externa) and their caliber are similar to those described by Damian (2007) who states that the external iliac artery is the true terminal of the common iliac artery (A. iliaca communis). The path of the external iliac artery and its branches are similar to those described by Eken et al. (2005).

Unlike the external iliac artery in horses, which gives off the deep circumflex iliac artery (A. circumflexa ilium profunda) and the deep femoral artery (A. profunda femoris) (Damian, 2007), in chinchillas, these branches have other origins. In the rabbit, contrary to the horse, the deep circumflex iliac artery (A. circumflexa ilium profunda) originates in the common iliac arteries (A. iliaca communis) (Barone, 1996).

Another particularity of chinchillas is the absence of the deep femoral artery (A. profunda femoris), a fact also mentioned by Eken et al.
(2005). The origin of the uterine artery (A. uterina) in chinchillas is different from that in other species. For instance, in the rabbit (Barone, 1996) and in the Guinea pig (Bell, 1968) the uterine artery $(A$. uterina) originates from the internal iliac artery (A. iliaca interna), and in the Black Bengal Doe (Haque, 2005), this artery is emitted in a common trunk with the umbilical artery, being considered the first branch of the internal iliac artery.

\section{CONCLUSION}

The terminals of the descending abdominal aorta in female chinchillas are two common iliac arteries (left and right), but can also be accompanied in some individuals by a third terminal - the median sacral artery.

The internal pudendal artery services the organs of the pelvic cavity, while the rest of the branches provide irrigation to the muscles of the pelvic cavity.

The uterine artery originates from the external iliac artery and the deep femoral artery is missing in female chinchillas.

The umbilical artery in female chinchillas represents one of the branches of the uterine artery. 
Acknowledgements. This paper was published under the frame of European Social Fund, Human Resources Development Operational Programme 2007-2013, project no. POSDRU/159/1.5/S/136893

\section{REFERENCES}

1. Çevik-Demirkana A, Özdemira V, Demirkan I (2010). The ovarian and uterine arteries in the chinchilla (Chinchilla lanigera), S. Afr. Vet. Ass. 81(1): 54-57.

2. Barone R, (1996). Anatomie comparee des mammiferes domestique; Tome 5, Angiologie Edition Vigot, Paris

3. Bud I, Ştefan R. (2006). Animale de blană; Ed. Risoprint, Cluj-Napoca

4. Bura M (2003). Chinchilla; Ed. Agroprint Timişoara

5. Botha M (2009). Influența factorilor de microclimat asupra perfofmanţelor de reproducție la Chinchilla (Chinchilla Laniger), Teză de doctorat.

6. Bell C (1968). Dual Vasoconstrictor and Vasodilator Innervation of the Uterine Arterial Supply in the Guinea Pig, Circ Res.23:279-290.

7. Damian A (2007). Anatomie Comparată, Sistemul Cardiovascular, Ed. AcademicPres, Cluj-Napoca.
8. Eken E, Besoluk K Teke BE (2005). An anatomical study on the conformation of the femoral artery in Chinchilla lanigera, Revue Méd. Vét., 156(10): 506-508.

9. Haque Z, Quasem MA, Karim MR, Khan MZI (2005). Arterial supply of the perineum of Black Bengal Doe. Bangl. J. Vet. Med. 3(1): 51-54.

10. Stan F, Gudea A, Damian A, Papuc I (2006). Particularities of collaterals and terminals of external iliac arteries in horse, Bull UASMV-MV, 63: 166-169.

11. Stan F, Damian A, Gudea A, Dezdrobitu C, Bob D, Martonos C, Bochis I, Pogana B (2014). Comparative anatomical study of the large intestine in rabbit and chinchilla. Bulletin of UASVM Cluj-Napoca,Veterinary Medicine, 71 (1):208-212.

12. Stan F (2013), Comparative Study Of The Stomach Morphology In Rabbit And Chinchilla. Agro Life Scientific Journal, Bucuresti, Romania, 2(2):73-78.

13. *** NOMINA ANATOMICA VETERINARIA, FIFTH EDITION (revised version), 2012, Published by the Editorial Committee Hannover (Germany), Columbia, MO (U.S.A.), Ghent (Belgium), Sapporo (Japan). 